\title{
A Contemporary View on Online and Web Tools for Students with Sensory \& Learning Disabilities
}

\author{
https://doi.org/10.3991/ijoe.v15i12.10833 \\ Vasiliki Bravou ( $\left.{ }^{\varpi}\right)$, Athanasios Drigas \\ N.C.S.R. Demokritos, Athens, Greece \\ vbravouliit.demokritos.gr
}

\begin{abstract}
In the last 30 years, the use of information and communication technologies, the evolution of hardware and software for special needs people, as well as the spreading of the World Wide Web, is assisting people with disabilities in overcoming obstacles, accessing information, learning and participating in activities, which otherwise were not able to carry out. Special needs education is the process adjusting the education of learners with disabilities according to their unique requirements. Evolvement of technology has made computers and mobile devices capable of complementing usual teaching processes for students with special needs. In this report we present a summary of some representative online applications for assisting disabled people in the learning process and their daily lives.
\end{abstract}

Keywords-Web-based application, online application, special education, special needs, physical disabilities, cognitive disabilities

\section{$1 \quad$ Introduction}

Disabilities are a broad term referring to sensory or physical impairments, activity restrictions and participation containment in life situations due to some cognitive disability. Consequently, disabilities are not just a matter of health. They are developed through the interplay of a health situation with environmental and private coefficients [1]. Physical disabilities consist of mobility, visual and hearing impairments. Mobility impairments indicate a decrease in the ability to move and use objects. Visual deficiencies comprise from low vision to blindness. Hearing impairments, range from having trouble in identification of sounds to complete deafness. Concerning cognitive disabilities, they consist of cognitive and intellectual insufficiencies, as language and learning disabilities, as well as mental disorders [1]. Cognitive disabled people face many kinds of restrictions, such as memory deficiency, lack of organizational skills, actions sequence, comprehension of complicated notions, as well as various intellectual procedures [2].

Education is a universal right and is meant to be accessible to everyone, including students with disabilities. Therefore, it is considered to be necessary to import alternative methods for the preparation of special education teachers and for engaging special education learners in a more efficient environment, according to their needs and 
eventually achieve social inclusion [3], [4]. Special needs education is the process adjusting the education of learners with disabilities according to their unique requirements [5]. In the last 30 years, evolvement of technology has made computers and mobile devices capable of complementing usual teaching processes for students with special needs [6]. The use of information and communication technologies, the evolution of hardware and software for special needs people, as well as the spreading of the World Wide Web, is assisting the latest in overcoming obstacles, accessing information, learning and participating in activities, which otherwise were not able to carry out [7], [8]. Online learning students are able to regulate the time, the place and the steps of the education process [9]. Special needs students and their teachers are capable of imitating a regular classroom through the use of their computer or mobile device. The first are preparing to face the difficulties of actual world via increasing their learning, writing skills and socialising with more students online.

\section{Sensory and Physical Disabilities}

Ubeid and Zaqout (2018) introduced "iCan", a web application framework which will allow sensory or physical impaired people to connect to transportation offices, to health care centers in order to be informed about health development programs, to shopping centers and markets so they can be supplied the requisite food and medicine and to connect with each other. Users with special needs will also be able to connect to training centers for the purpose of being informed about new courses in their field. Parents or carers of the disabled users will be educated through the platform on how to handle them. The application is going to be designed using PHP Laravel, JavaScript, jQuery, HTML5, CSS3 and Bootstrap [10].

In 2017, Tongkaw presented the Geographical Information Systems (GIS), for people with disabilities. The system is responsible for storing the location coordinates, the types of disabilities and other captured data of impaired users, store them in a database, in order to be displayed through the Google API on the Google Map. Users with physical impairments, as well as cognitive disabilities, are presented in the map in the form of spatial data, with the purpose of recording the quantity of people with special needs in any area or the amount and type of their disabilities. The platform of the GIS system is developed by Java and PHP. Java Runtime Environment (JRE), as well as a PHP installation with the support of JavaScript Object Notation (JSON) are required for the server [11].

In 2013, Jemaa et al. completed a study about e-accessibility, universal design and assistive technologies for people with disabilities, which focuses on e-learning systems. In particular, the accessible version "MoodleAcc+" of the e-learning platform Moodle, is presented, as well as tools about authorship and evaluation of educational content. The developed UML meta-model, for accessible e-learning systems, called ACCUML, permits adjustment, alteration and flexibility, regarding personalised learning experiences for each user. It is designed by OMG Model Driven Architecture (MDA), based on Model view Systems [12]. 
In 2014, Prandi et al introduced mPass (mobile Pervasive Accessibility Social Sensing), a prototype application for Android systems and web browsers, designed for aiding people with special needs. The system is providing personalised maps, paths and routes, for the purpose of improving urban accessibility. The information about routing provided is generated by devices' sensors and data obtained through the use of the system by each user [13].

Cheung et al. presented in 2017 the build and analysis of a robot avatar, which is responsible for taking pictures or videos and providing them to the user through a head mount device. The purpose of the robot is to aid people with disabilities increase their social interactions and visit places, which would otherwise be unreachable. The user is able to control the movement of the avatar via the finger gesture recognition system installed. An Arduino program is used for moving the robot and hand gestures are recognised by a Windows/Linux $\mathrm{C}++$ program [14].

In 2016, Crespo et al., developed a platform, named Social4all, for the purpose of analysing websites and distinguish the possible accessibility problems of the latest, for people with visual, hearing and neurological impairments. Sufficient solutions are proposed for each inserted Uniform Resource Locator (URL), without modifying the original code of the website. The suggested solutions consist of previous users' adaptations and are retrieved from the Social4all global repository. The client of the platform is developed using JavaServer Pages, Java, Servlets, Web Services, JavaScript, jQuery, HTML and CSS. The web application is running in a Tomcat 7 Server and connects to a MySQL Database [15].

Debevc et al. presented in 2014 the development and usage of a web-based, modifiable e-learning system for deaf or hard-of-hearing people. The courses of the system are consisted of videos with explanation in sign language, subtitles and were based on the learning management system Moodle. Results from the study indicate the elearning system is proper for people with the above-mentioned disabilities and fits their needs [16].

In 2017, Gehret et al. conducted a study for teaching STEM from distance to deaf or hard-of-hearing students. For communication purposes, between tutor and students, Google Hangouts platform was used and for scheduling session appointments Google Calendar was utilised, in a Chrome web browser. iSight camera in an iMac was preferred for the tutor and an online whiteboard was agglomerated with the aid of Conceptboard application, a stylus and an iPad. In that way, special needs students were taught biochemistry and general chemistry, remotely [17].

In 2018, Alkhalifa and Al-Razgan, introduced Enssat, a hearing aid application for the deaf and hard-of-hearing people. In this study, the application was installed on the Android platform of a smart phone, which in cooperation with a Google Glass, allows the user to translate every ongoing discourse close to him and display it in the Google Glass display, in one of the 14 available languages. Google's Speech-to-Text service is used for the purpose of transcribing the sounds heard around the mobile phone device. Another function of the system is the available alerts for the alarming surrounding sounds. The interface of the application is bilingual (English and Arabic) [18]. 


\section{Cognitive Disabilities}

\subsection{Autistic spectrum disorder}

Garcia et al. introduced in 2016, an adaptive web-based application to assist students with autism embody in high education. The toolkit's functionality alters depending on whether the user is autistic or not, a function that is based on learning styles and user history. The application's settings screen was primarily tried by autistic students, who were unable to comprehend its usage. Alterations to the privacy settings would be beneficial to prevent anxiety caused to the participants. The toolkit of the application is implemented using Wordpress, a Content Management System (CMS), having combined a client-side adaptation library called WiBAF [19].

In 2015, Hulusic and Pistoljevic, introduced a web-based interactive educational ebook for teaching children with developmental disabilities, like Autism Spectrum Disorder (ASD). The above-mentioned e-book, designed as a serious game, in comparison to printed books, is able to capture and retain the students' attention and provide them the opportunity for learning in ways customised to their needs. Users are able to listen to the bilingual narrated pages, in the form of scenes, allowing them to learn a foreign language, between Bosnian-Croatian-Serbian and English. HTML5, CSS3, JavaScript, jQuery and Ajax were used for developing the e-book [20].

In 2014, Şimdi et al. developed a web-based application assisting children with autism improve their sequencing skill. The study was conducted in Turkey and three sessions were completed, consisting of an initial testing, a teaching and a final testing session. The application was assistive for children around 11 years old, but not helpful for the rest of the sample, because of the lack of different levels of difficulty. HTML5, CSS3, Jquery, MySQL, PHP and Ajax were used for the construction of tool [21].

Pavlov, in 2014, introduced the user interface of Open Book, an assistive tool for people with autism spectrum disorder (ASD) and other reading comprehension difficulties, in order to ameliorate the difficulties that these people confront in reading and understanding online content. Open Book is designed by using a distributed architecture and utilises diverse natural-language-processing (NLP) techniques to make documents simpler, helping out autistic users in the reading process. HTML5, CSS3 with Media Queries and JavaScript were used for designing the web-based application [22].

Rakap et al. proposed in 2015 a web-based professional development program, as part of the Project Autism Competencies for Endorsement (ACE). The software was created in order to deploy and ameliorate the abilities and cognition, as well as educate teachers assisting children with Autism Spectrum Disorder (ASD), about the various special needs of the latter. Five instructors participated in the two-year program, which consisted of four online courses and two field experiences, for the purpose of putting into practice the knowledge acquired from the courses [23]. 


\subsection{Difficulties in reading-writing and mathematics}

Bakker et al. presented in 2016 a series of online teacher-led mathematics minigames, assisting in multiplicative reasoning ability of students' with special needs. Students from five schools, for special primary education, participated in the study and everyone's aforementioned ability was considerably augmented. The mini-games were accessible online through the Digital Mathematics Environment (DME) and different difficulty levels were offered. Inviting environment of games, proved to be a motivating factor for special education students to develop their declarative knowledge of multiplicative relations [24].

Straub and Vasquez III presented, in 2015, an online guidance of writing for students with learning disabilities. In this study, POW (Pick my ideas, Organise my notes, Write and say more) and TREE (Topic sentence, Reasons, Ending, Examine) self-regulated strategy model for persuasive and argumentative writing, is investigated for its effectiveness. Adobe Connect is utilised as a video-conferencing platform and as a memorization of writing strategies tool and Google Docs is used for cooperative writing activities and for producing momentary development graphs [25].

\subsection{Dyslexia}

In 2016, Rello et al. presented a computer-based online chess game, implemented in order to comprehend dyslexic people's learning styles in comparison to other students' in a control group, through their chess play learning. Experimental results suggest that people with dyslexia need more time to learn chess theory, complete chess exercises and play web-based chess, because of text decoding failure, visuospatial attention disorder and dyscalculia that often affect this group of people. This study showed that dyslexia might influence chess performance; hence chess training could be related to dyslexia revelation [26].

Alghabban et al., in 2017, introduced a mobile cloud-based learning tool, addressing students with dyslexia, who can interact depending on their unique learning style. The proposed tool, with multimodal support, aims to assist students with dyslexia, providing useful data for learning and comprehending purposes. The tool is adaptable to its learner's profile and learning style preference, showing the content through audio, text and images, motivating students in the learning process. The purpose of this study is to detect if it is possible to ameliorate the dyslexic students' ability to read, using the above-mentioned tool [27].

Pirani and Sasikumar proposed in 2015, a web-based Assistive Learning Environment (ALE), accessible by browsers, to increase learning capability of students with learning difficulties. These difficulties are often classified as speech and language disorder, academic disorder and other non-verbal disorder. The online tutorials and course content are adaptable to each learner's difficulty and to specific content that will be delivered to them. The Assistive E-Learning System was developed with PHP, XML and HTML. Based on the results of this study, the variety of subjects and their analysis is satisfactory, according to the different disabilities of learners [28]. 


\subsection{Mental disorders}

In 2016, Chatzara et al. presented the design of an emotional agent, capable of providing cognitive support to people with learning difficulties and attention disorders. The target group of the study is students in higher education, in information technology domain, with difficulties as mentioned above. An agent with emotional conduct, made with I-Clone software, was used and its application ran online. Results indicated that responses of the aforementioned agent, that included empathy, enhanced communication of the participants, leading to efficient integration of practice tasks and also lead to contented users. Further research needs to be implemented, in order to examine the impact of agents in broader learning groups [29].

Pereira et al. developed in 2014 a web-based interactive program to teach primary school educators about mental disorders in childhood. The program consists of a homepage of the website, a learning management system (LMS) tutorial, educational videos, a Strengths and Difficulties Questionnaire (SDQ) tutorial, an Internet discussion forum, a web conference and written support text. Schools from Brazil participated in the study and results presented a growth of teachers' knowledge about psychiatric disorders, which indicate superiority of internet-based tool over traditional text and video materials [30].

In 2015, Roepke et al. presenter SuperBetter, a web-based tool, designed as a game, which aims in relieving depression. The tool is accessible via a smartphone or the SuperBetter's website. Two versions of the tool were tested and both turned out to be effective. The first is designed specifically for depression and is using known therapies (CBT and PPT). The other is more general and not designed specifically for depression. Results showed that participants using the program managed to decrease their depressive symptoms [31].

Ly et al. presented, in 2014, two applications for the purpose of evaluating and comparing the effectiveness of behavioural activation and mindfulness, as methods for treating mild-to-moderate major depression. Results from this study, show that behaviour activation operates better with major depression, whilst mindfulness works better with mild depression. Both applications were implemented, as iPhone applications, using objective $\mathrm{C}$ programming language and as mobile web applications for other smartphones [32].

\section{Conclusion}

Learning requirements of disabled people are various. They must gain the knowledge and abilities needed, in order to cope with the demands of their society. Furthermore, people with special needs, have additional demands, in the sense of special educational needs, resulting from practical restrictions which have an impact in the learners' capability to access formal educational procedures. Assistive technologies and online applications, in particular, are helpful to people with disabilities as, the latest can be more independent in their daily lives and be able to carry out activities, without the aid of their carers or another person. Learners and users of this kind 
of applications, are capable of regulating the speed, the place and the time for utilise the assistive software, according to their needs.

In spite of the laws against the unjust or prejudicial treatment of different categories of people, especially people with special needs, in Europe, statistical studies indicate that the access of the latest to innovative technologies is still difficult. Alterations of the accessibility enactment are obligatory towards a reachable Web [35]. With the purpose of improving the learning performance and the day to day lives of special needs people, a large amount of work is still required in the area of web-based applications for disable people and special education in particular.

\section{$5 \quad$ References}

[1] P. Maurya, "Technology Supported Education for People with Disabilities," TechnoLearn: An International Journal of Educational Technology, vol. 7, no. 1 and 2, pp. 35-44, 2017. https://doi.org/10.5958/2249-5223.2017.00004.3

[2] R. Nour, "Web searching by individuals with cognitive disabilities," ACM SIGACCESS Accessibility and Computing, no. 111, pp. 19-25, 2015. https://doi.org/10.1145/2809904. $\underline{2809909}$

[3] L. Scott and P. Temple, "A conceptual framework for building udl in a special education distance education course," Journal of Educators Online, vol. 14, no. 1, 2017.

[4] P. A. Cinquin, P. Guitton, and H. Sauzéon, "Online e-learning and cognitive disabilities: A systematic review," Computers and Education, vol. 130, pp. 152-167, 2019. https://doi. org/10.1016/i.compedu.2018.12.004

[5] P. Vidhya and J. Meena Kumari, "Analysis and Evaluation of Computer Apps for Special Education," International Journal of Advanced Research, vol. 4, no. 4, pp. 1620-1625, 2016.

[6] M. W. Ok, M. K. Kim, E. Y. Kang, and B. R. Bryant, "How to find good apps: An evaluation rubric for instructional apps for teaching students with learning disabilities," Intervention in School and Clinic, vol. 51, no. 4, pp. 244-252, 2016. https://doi.org/10.1177/1053 451215589179

[7] T. Lersilp and S. Lersilp, "A Guideline of using Assistive Technologies and Educational Services for Students with Disabilities in Higher Education," American Journal of Applied Sciences, vol. 14, no. 5, pp. 526-532, 2017. https://doi.org/10.3844/ajassp.2017.526.532

[8] D. Bjekić, S. Obradović, M. Vučetić, and M. Bojović, "E-teacher in Inclusive e-education for Students with Specific Learning Disabilities," Procedia - Social and Behavioral Sciences, vol. 128, pp. 128-133, 2014. https://doi.org/10.1016/j.sbspro.2014.03.131

[9] J. D. Basham, R. A. Carter, M. F. Rice, and K. Ortiz, "Emerging State Policy in Online Special Education," Journal of Special Education Leadership, vol. 29, no. 2, pp. 70-78, 2016.

[10] M. Ubeid and I. Zaqout, "iCan - A Web Application Framework for People with Special Needs," International Research Journal of Innovations in Engineering and Technology, vol. 2, no. 4, pp. 18-27, 2018.

[11] S. Tongkaw, "GIS Application Management for Disabled People," IOP Conference Series: Materials Science and Engineering, vol. 226, no. 1, p. 012112, 2017. https://doi.org/10.10 $\underline{88 / 1757-899 x / 226 / 1 / 012112}$

[12] M. Laabidi, M. Jemni, L. Jemni Ben Ayed, H. Ben Brahim, and A. Ben Jemaa, "Learning technologies for people with disabilities," Journal of King Saud University - Computer and 
Information Sciences, vol. 26, no. 1, pp. 29-45, 2014. https://doi.org/10.1016/j.jksuci.20 13.10 .005

[13] C. Prandi, P. Salomoni, and S. Mirri, "mPASS: Integrating people sensing and crowdsourcing to map urban accessibility," in 2014 IEEE 11th Consumer Communications and Networking Conference (CCNC), 2014, pp. 591-595. https://doi.org/10.1109/ccnc. $\underline{2014.6940491}$

[14] C. W. Cheung, T. I. Tsang, and K. H. Wong, "Robot Avatar: A Virtual Tourism Robot for People with Disabilities," International Journal of Computer Theory and Engineering, vol. 9, no. 3, pp. 229-234, 2017. https://doi.org/10.7763/ijcte.2017.v9.1143

[15] R. G. Crespo, J. P. Espada, and D. Burgos, "Social4all: Definition of specific adaptations in Web applications to improve accessibility," Computer Standards and Interfaces, vol. 48, pp. 1-9, 2016. https://doi.org/10.1016/j.csi.2016.04.001

[16] M. Debevc, Z. Stjepanovič, and A. Holzinger, "Development and evaluation of an elearning course for deaf and hard of hearing based on the advanced Adapted Pedagogical Index method," Interactive Learning Environments, vol. 22, no. 1, pp. 35-50, 2014. https://doi.org/10.1080/10494820.2011.641673

[17] A. U. Gehret, L. B. Elliot, and J. H. MacDonald, "Active Collaborative Learning Through Remote Tutoring," Journal of Special Education Technology, vol. 32, no. 1, pp. 36-46, 2017.

[18] S. Alkhalifa and M. Al-Razgan, "Enssat: wearable technology application for the deaf and hard of hearing," Multimedia Tools and Applications, vol. 77, no. 17, pp. 22007-22031, 2018. https://doi.org/10.1007/s11042-018-5860-5

[19] A. M. García, P. De Bra, N. Stash, G. H. L. Fletcher, M. Fabri, and M. Pechenizkiy, "Adaptive web-based educational application for autistic students," in CEUR Workshop Proceedings, 2016, vol. 1628.

[20] V. Hulusic and N. Pistoljevic, "Read, play and learn: an interactive e-book for children with autism," in International Conference on Games and Learning Alliance, 2015, pp. 255-265. https://doi.org/10.1007/978-3-319-40216-1 27

[21] C. Doenyas, E. Şimdi, E. Ç. Özcan, Z. Çataltepe, and B. Birkan, "Autism and tablet computers in Turkey: Teaching picture sequencing skills via a web-based iPad application," International Journal of Child-Computer Interaction, vol. 2, no. 1, pp. 60-71, 2014. https://doi.org/10.1016/j.ijcci.2014.04.002

[22] N. Pavlov, "User Interface for People with Autism Spectrum Disorders," Journal of Software Engineering and Applications, vol. 07, no. 02, pp. 128-134, 2014. https://doi.org/10. 4236/jsea.2014.72014

[23] S. Rakap, H. A. Jones, and A. K. Emery, "Evaluation of a web-based professional development program (project ACE) for teachers of children with autism spectrum disorders," Teacher Education and Special Education, vol. 38, no. 3, pp. 221-239, 2015. https://doi.org/10.1177/0888406414535821

[24] M. Bakker, M. van den Heuvel-Panhuizen, and A. Robitzsch, "Effects of mathematics computer games on special education students' multiplicative reasoning ability," British Journal of Educational Technology, vol. 47, no. 4, pp. 633-648, 2016. https://doi.org/ $10.1111 /$ bjet.12249

[25] C. Straub and E. Vasquez III, "Effects of Synchronous Online Writing Instruction for Students With Learning Disabilities," Journal of Special Education Technology, vol. 30, no. 4, pp. 213-222, 2015. https://doi.org/10.1177/0162643415618929

[26] L. Rello, S. Subirats, and J. P. Bigham, "An online chess game designed for people with dyslexia," in Proceedings of the 13th Web for All Conference, 2016, p. 28. https://doi.org/10.1145/2899475.2899479 
[27] W. G. Alghabban, R. M. Salama, and A. H. Altalhi, "Mobile cloud computing: An effective multimodal interface tool for students with dyslexia," Computers in Human Behavior, vol. 75, pp. 160-166, 2017. https://doi.org/10.1016/j.chb.2017.05.014

[28] Z. Pirani and M. Sasikumar, "Assistive e-learning system for the learning disabled," Procedia Computer Science, vol. 45, pp. 718-727, 2015. https://doi.org/10.1016/i.procs.2015. $\underline{03.139}$

[29] K. Chatzara, C. Karagiannidis, and D. Stamatis, "Cognitive support embedded in selfregulated e-learning systems for students with special learning needs," Education and Information Technologies, vol. 21, no. 2, pp. 283-299, 2016. https://doi.org/10.1007/s10639014-9320-1

[30] C. A. Pereira, C. L. Wen, E. C. Miguel, and G. V. Polanczyk, "A randomised controlled trial of a web-based educational program in child mental health for schoolteachers," European Child and Adolescent Psychiatry, vol. 24, no. 8, pp. 931-940, 2015. https://doi.org/ 10.1007/s00787-014-0642-8

[31] A. M. Roepke, S. R. Jaffee, O. M. Riffle, J. McGonigal, R. Broome, and B. Maxwell, "Randomized Controlled Trial of SuperBetter, a Smartphone-Based/Internet-Based SelfHelp Tool to Reduce Depressive Symptoms," Games for Health Journal, vol. 4, no. 3, pp. 235-246, 2015. https://doi.org/10.1089/g4h.2014.0046

[32] K. H. Ly et al., "Behavioural activation versus mindfulness-based guided self-help treatment administered through a smartphone application: A randomised controlled trial," BMJ Open, vol. 4, no. 1, p. e003440, 2014. https://doi.org/10.1136/bmjopen-2013-003440

[33] D. Ferri and S. Favalli, "Web Accessibility for People with Disabilities in the European Union: Paving the Road to Social Inclusion,” Societies, vol. 8, no. 2, p. 40, 2018. https://doi.org/10.3390/soc8020040

\section{Authors}

Vasiliki Bravou is a member of N.C.S.R. "Demokritos", Institute of Informatics and Telecommunications - Net Media Lab \& Mind-Brain R\&D, Agia Paraskevi 153 10, Athens, Greece (e-mail: vbravou@,iit.demokritos.gr).

Athanasios Drigas is a Director of Research at N.C.S.R. 'Demokritos', Institute of Informatics and Telecommunications, and a Coordinator of Net Media Lab \& BrainMind R\&D, Agia Paraskevi, 153 10, Athens, Greece (e-mail: dr@iit.demokritos.gr).

Article submitted 2019-05-09. Resubmitted 2019-05-29. Final acceptance 2019-05-29. Final version published as submitted by the authors. 